\title{
PALAVRA ÚMIDA - POR UMA ABORDAGEM FENOMENOLÓGICA DO ESPETÁCULO "RIO DE CONTAS"
}

\author{
PALABRA ÚMIDA - POR UN ENFOQUE FENOMENOLÓGICO DEL \\ ESPECTÁCULO "RÍO DE CUENTAS"
}

\section{WASTE WORD - BY A PHENOMENOLOGICAL APPROACH OF THE SHOW "RIO DE ACCOUNTS"}

\begin{abstract}
André Vitor Brandão da Silva ${ }^{1}$
\section{Resumo}

O artigo se situa na emergência da problematização em torno da abordagem metodológica da fenomenologia na pesquisa em educação e dança contemporânea, objetivando compreender como essa abordagem contribui para a compreensão da dança contemporânea no Vale do São Francisco e seu potencial educativo contextualizador das realidades locais através do corpo. Considerando que, a dança e a educação como fenômenos da vida humana são mais bem investigados pela perspectiva fenomenológica que, através de seu método, traz a superfície, os pormenores das relações estabelecidas entre os sujeitos e o mundo nos mais diversos campos da vida humana para que, assim, possamos conhecer o outro, o mundo e a nós mesmos de maneira mais profunda.
\end{abstract}

Palavras-Chave: Metodologia. Fenomenologia. Dança Contemporânea. Educação.

\section{Resumen}

El artículo se sitúa en la emergencia de la problematización en torno al enfoque metodológico de la fenomenología en la investigación en educación y danza contemporánea, con el objetivo de comprender cómo este enfoque contribuye a la comprensión de la danza contemporánea en el Valle del San Francisco y su potencial educativo contextualizador de las realidades locales a través del medio cuerpo. Considerando que la danza y la educación como fenómenos de la vida humana están mejor estudiados por la perspectiva fenomenológica que, a través de su método, trae la superficie, los detalles de las relaciones establecidas entre los sujetos y el mundo en los más diversos campos de la vida humana que, así, podamos conocer al otro, el mundo ya nosotros mismos de manera más profunda.

Palabras clave: Metodología. La fenomenología. Danza contemporanea. Educación.

\footnotetext{
${ }^{1}$ Licenciado em Artes Visuais pela Universidade Federal do Vale do São Francisco (UNIVASF), especialista em Dança Educacional e Artes Cênicas pela Faculdade São Fidelis, e mestrando em Educação, Cultura e Territórios Semiáridos pelo PPGESA da Universidade do Estado da Bahia (UNEB).
} 


\begin{abstract}
The article focuses on the emergence of problematization around the methodological approach of phenomenology in research in contemporary education and dance, aiming to understand how this approach contributes to the understanding of contemporary dance in the São Francisco Valley and its educational potential contextualizing local realities through body. Considering that dance and education as phenomena of human life are best investigated by the phenomenological perspective which, through its method, brings the surface, the details of the relations established between subjects and the world in the most diverse fields of human life to so that we may know the other, the world and ourselves in a deeper way.
\end{abstract}

Keywords: Methodology. Phenomenology. Contemporary dance. Education.

\title{
Corpo, dança e educação: confluências possíveis
}

Pensar a educação através do corpo, de imediato, evoca uns cem números de problemáticas que resvalam, inevitavelmente, na política, na ética e na estética. Em certas correntes de pensamento não-hegemônicas, na ciência e na filosofia, o corpo é entendido não como "morada" de um EU abstrato, mas sendo ele mesmo encarnado, logo, somos nosso próprio corpo (MERLEAU-PONTY, 1994). Dessa maneira, a realidade desse corpo emerge de maneira paradoxal, pois, na simplicidade da vida cotidiana ele se desdobra multidimensional, estabelecendo relações complexas com o mundo a sua volta. Destarte, corpo e mundo constroem e emprestam sentidos um ao outro (MERLEAU-PONTY, 1999).

Entretanto, os processos educativos nos dias atuais forjam, a todo instante, mecanismos de secundarização e controle dos corpos. A educação da qual poderíamos dizer hegemônica, parece se relacionar com a atualidade de forma anacrônica, na medida em que se mantêm arraigada na peleja dicotômica: mente versus corpo. Nessa perspectiva, os processos advindos do corpo são entendidos como elementares e os provenientes da mente como superiores. Merleau-Ponty (1994) tece uma crítica a esse ponto de vista, discorrendo que:

O elementar não é mais aquilo que, por adição, constituirá o todo, nem aliás uma simples ocasião para o todo se constituir. $\mathrm{O}$ acontecimento elementar já está revestido de um sentido, e a função superior só realizará um modo de existência mais integrado ou uma adaptação mais aceitável, utilizando e sublimando as operações subordinadas (MERLEAU-PONTY, 1994, p. 31).

Desse modo, o autor nos coloca, portanto, que a dicotomia razão versus emoção não dá conta da complexidade do corpo, sendo necessário abordá-lo de modo multifacetado. 
Por seu turno, Focault (1987) nos coloca a pensar sobre o disciplinamento dos corpos como fundantes na manutenção de poderes hegemônicos basilares na sociedade moderna. Sobre o assunto, o autor (1987) comenta que:

\begin{abstract}
Aprender a comportar-se, movimentar-se, ser preciso e ter ritmo. Gestos são fabricados, e sentimentos são produzidos. Este adestramento é resultado da aplicação de técnicas positivas de sujeição baseadas em saberes pedagógicos, médicos, sociológicos, físicos etc. O corpo torna-se útil e eficiente, mas ao mesmo tempo torna-se dócil e submisso: o corpo só se torna força útil se é ao mesmo tempo corpo produtivo e corpo submisso (FOUCAULT, 1987, p. 28).
\end{abstract}

Existe na educação, um ideal disciplinatório dos corpos que controla os gestos e as identidades. A escola, portanto, é um lugar para vigiar e punir, onde o poder se encarna e produz saber, terreno propício para a gesta de condutas assimétricas de poderes que, inevitavelmente, regem nossa vida em sociedade. Portanto, o corpo se torna objeto de produção material e tem sua potência reduzida na execução de atividades, puramente, pragmáticas do trabalho.

A educação através da dança, por seu lado, propõe a elaboração de conhecimentos e sentidos através do corpo em relação com o mundo, entende o sujeito como um ser-no-mundo (HEIDEGGER, 1995), colocando o corpo como epicentro da aprendizagem. Propondo um processo de criação que une política, ética e estética em torno da edificação de uma corporeidade. Nesse sentido, Nóbrega (1999) argui que:

A noção de corporeidade trata das potencialidades do corpo, designando-o
em sua auto-organização criativa plena de possibilidades que, talvez, só a
natureza estética em seu aspecto sensível, que une vivência e conceito, possa
expressar com plenitude (NÓBREGA, 1999, p. 28).

Dessa maneira, a corporeidade enfatiza as potências e possibilidades que o corpo que dança, e que através do movimento e da experiência que o ato de dançar fornece, produz conhecimentos e saberes sobre o mundo. Assim, são estas problemáticas que motivam a realização do projeto de mestrado intitulado "Corpos Flutuantes- estratégias de emancipação e aprendizagem através da dança produzida no Vale do São Francisco" que está em andamento no programa de Mestrado em Educação, Cultura e Territórios Semiáridos (PPGESA). Destarte, a partir das problemáticas apresentadas acerca do corpo, da dança e da educação, a pesquisa se propõe a pensar o processo criativo do espetáculo "Rio de Contas" da Cia. de Dança do Sesc- Petrolina- PE como sendo um processo de ensino aprendizagem que perpassa 
o corpo, a política, a ética e a estética que, por sua vez, constrói corpos e imagens emancipadas e contextualizadas as realidades locais.

Contudo, objetivamos neste artigo compreender como a abordagem fenomenológica contribui para compreensão da dança contemporânea no Vale do São Francisco e seu potencial educativo e contextualizador das realidades locais através do corpo. Assim, construiremos uma cartografia metodológica do projeto, buscando descortinar caminhos e apurar olhares necessários ao bom desenvolvimento da pesquisa.

Vale salientar, que em um estudo que se propõe investigar fenômenos sociais, educacionais e artísticos que, em essência, são dinâmicos, nebulosos e mutáveis, a metodologia, previamente estabelecida, serve de mapa, guia prévio para não nos perdermos no campo. Entretanto, a metodologia se consolida no corpo a corpo da pesquisa, no momento de sua feitura.

\section{Rio de Contas- por um devir-rio}

Um espetáculo de dança surge como um rio. As motivações e desejos para a criação gestam nos corpos de maneira silenciosa, parece que esperam o momento apropriado para encarnarem. O espetáculo aos poucos vai se instaurando e quando menos esperamos, ele já está lá, brotando como água numa nascente. Nessa perspectiva, Lara (2010) discorre que:

No ato da criação repensamos o mundo. Criamos quando organizamos uma forma sensível de apresentar uma nova configuração daquilo que já conhecemos. Durante o processo criativo, é a partir de nossa percepção que transportamos o que apreendemos do concreto, do vivido e do imaginado para uma obra artística (LARA, 2010, p. 35).

Por sua vez, o espetáculo "Rio de Contas" que é objeto de estudo da pesquisa "Corpos Flutuantes- estratégias de emancipação e aprendizagem através da dança produzida no Vale do São Francisco" articulou em sua criação questões advindas do modo como percebemos e experienciamos o ser/estar no Vale do São Francisco por meio das relações que estabelecemos com o rio que atravessa nossa região. Desse modo, interessa a pesquisa problematizar os processos que deram origem ao espetáculo, assim como, as reverberações imagéticas, culturais e sociais que foram acionadas em seu processo de criação, e que são revistas toda vez que o espetáculo é novamente apresentado.

Posto isso, podemos perceber no processo de construção de um espetáculo de dança um caráter, eminentemente educativo, que imbrica a articulação das dimensões subjetivas, 
estéticas e de contexto sociocultural. Assim, o processo de construção de um espetáculo se configura como um espaço não formal de aprendizagem. No caso do espetáculo "Rio de Contas", o mesmo, poderia ser entendido como um lugar de educação contextualizada, já que, tem como vetor os modos de ser e viver da região do Vale do São Francisco com ênfase nas relações que são estabelecidas com e a partir do rio.

Os processos de aprendizagem desenvolvidos a partir do espetáculo se edificam no corpo, a partir da experiência de dançar o mundo vivido, de significar o que nos cerca a partir do movimento. Portanto, não se trata de aprender um assunto e/ou uma determinada "disciplina", mas ao mesmo tempo, elaborar e apreender os assuntos escritos pelo movimento a partir da relação corpo/mundo-da-vida. Configurando-se assim, numa educação como poesia (MARTINS, 1992), ou ainda como uma espécie de devir-educação que tem em seu cerne, um ideal de transformação dos sujeitos.

Assim, o espetáculo "Rio de Contas" em sua gestação trouxe aos corpos o reclame da metamorfose, uma necessidade primeira de pensar o corpo para além das fronteiras préconcebidas dele. Logo, os corpos se fizeram em devir-rio. Deleuze e Guattari (1997) comentam que:

Devir é, a partir das formas que se tem, do sujeito que se é, dos órgãos que se possui ou das funções que se preenche, extrair partículas, entre as quais instauramos relações de movimento e repouso, de velocidade e lentidão, as mais próximas daquilo que estamos em vias de devir, e através das quais devimos. É nesse sentido que o devir é o processo do desejo (DELEUZE; GUATTARI, 1997, p. 67).

Colocar o corpo em devir, é fazê-lo experienciar o mundo de outra maneira, pois, há sempre mais modos de perceber a vida do que podemos descrever. Desse modo, os corpos no espetáculo se fizeram em devir-rio numa busca por encontrar uma presença de co-vizinhança, um lugar dialógico de dupla captura na busca de uma experiência, uma aprendizagem singular sobre o rio e os modos de relação que estabelecemos com ele no Vale do São Francisco.

Não há como sair ileso dessa experiência, já que o processo de aprendizagem se dá em viés de dupla estruturação, pois, não se recebe um determinado conhecimento já préelaborado, mas o constrói na mesma medida em que se apreende. Porpino (2006), afirma que:

A vivência estética é a experiência da beleza, da sensibilidade, da descoberta do sentido na vida cotidiana. Compreender a experiência estética e vive-la plenamente é, portanto, poder abrir novos caminhos para a compreensão não-fragmentada da existência humana, transgredindo a visão racionalista e levando à educação uma concepção de ser humano que possa transgredir a visão dicotomizada ainda predominante (PORPINO, 2006, p. 19). 
É através da estética, da política e da ética que pensamos a educação como lugar de emancipação, como possibilidade de apreensão e ressignificação do mundo de modo criativo e humanizante. A dança, portanto, enquanto campo de aprendizagem através do corpo se faz terreno fértil para o desenvolvimento dessa perspectiva de educação que se edifica a partir da corporeidade.

Pressupomos nesse estágio inicial de desenvolvimento da pesquisa, que as experiências proporcionadas pelo devir-rio, além de terem um valor em si mesma, puderam expandir a compreensão do que pode um corpo, das camadas e dimensões que podemos acessar quando nos colocamos em devir. Portanto, levantamos como hipótese que a ideia de devir-rio no espetáculo se fez educação, na medida em que erigiu saberes e modos de perceber o mundo de maneiras outras.

\section{Palavra úmida- as experiências e os fenômenos}

Em se tratando da abordagem metodológica que faremos para o desenvolvimento da pesquisa de mestrado "Corpos Flutuantes- estratégias de emancipação e aprendizagem através da dança produzida no Vale do São Francisco" terá como base os pressupostos da Fenomenologia, que a partir de seus conceitos básicos de descrição, redução, experiência, percepção e intencionalidade propõe uma análise rigorosa dos fenômenos presentes no mundo da vida. Portanto, a partir da fenomenologia, investigaremos o fenômeno da dança contemporânea no Vale do São Francisco como espaço potente de construção de imagens e corpos emancipados que se dão através de processos de ensino-aprendizagem por meio do corpo.

Foi em 1900, com a publicação do texto "Recherches Logiques" que Edmund Husserl (1859-1938) nos apresentou os pressupostos da Fenomenologia, trazendo com ela a abertura de um vasto campo de conhecimento e atuação nas ciências, que ainda hoje frutificam estudos nos mais diversos campos do conhecimento. A Fenomenologia diz respeito ao estudo dos fenômenos e como estes nos chegam a consciência "[...] exatamente como isso se apresenta; ou, em outras palavras, a fenomenologia é o estudo das estruturas da consciência" (GIORGI, 2017, p. 386).

Dessa maneira, entendemos o espetáculo "Rio de Contas" enquanto fenômeno, uma presença poética que engendra processos de educação não institucionalizados que articulam pressupostos éticos e estéticos. Cabe, portanto, perguntarmo-nos: de que maneira a experiência de participar de um processo criativo de um espetáculo de dança contemporânea 
contribui para a formação de um sujeito consciente de sua singularidade-plural, construindo para si uma corporeidade capaz de fazê-lo sentir, pensar e experienciar o mundo sob perspectivas não hegemônicas?

Para tal, precisaremos recorrer às ideias de percepção desenvolvidas por Merleau- Ponty (1992), das quais o autor nos fala que a percepção é uma ação do/no corpo que se direciona a apreensão do mundo, a construção de conhecimento sobre este de forma corporificada. É a partir da reversibilidade, ou seja, da compreensão de que corpo e mundo se relacionam de modo mútuo, que os sujeitos conseguem se perceber enquanto seres condicionados a experiências no mundo-da-vida. Assim, "Antes da ciência do corpo - que implica a relação com outrem -, a experiência de minha carne como ganga de minha percepção ensinou-me que a percepção não nasce em qualquer outro lugar, mas emerge no recesso de um corpo" (MERLEAU-PONTY, 1992, p. 21).

A corporeidade em associação a ideia de percepção reclama pela possibilidade de entendimento do corpo dotado de uma singularidade que se constitui a partir da pluralidade de outros corpos, assim como, constructo de conhecimento a partir da coexistência das dimensões múltiplas que nos constituem, ou seja, um conhecimento que não se edifica em condutas dicotômicas como, por exemplo, a partir de relações assimétricas de importância entre razão e emoção. Segundo, Porpino (2006)

[...] a Corporeidade desvela o corpo em sua essência existencial complexa. Restitui a este a sua capacidade de gerar conhecimento, de reconhecer-se como sujeito da percepção, sendo ao mesmo tempo objeto percebido por outros corpos, numa época (século XX) em que a predominância do racionalismo ainda se faz presente (PORPINO, 2006, p. 63).

O espetáculo "Rio de Contas", por seu turno, propôs aos seus intérpretes uma investigação corporal de outros modos de perceber o corpo em relação com o mundo, mais especificamente, com o rio. Através de exercícios de criação e entrevistas com pescadores e ilhéus da comunidade do Massangano, é que os bailarinos puderam experimentar estados corporais outros, que, por sua vez, foram acionados a partir das vivências de corpo no rio e das histórias contadas pelos beradeiros. Nesse sentido, é que o devir se fez operação teóricaprática para encontrar esse território simbiótico de corpo-rio, pois:

Não podemos confundir o devir nem com semelhança, nem com analogia. Ele é real, muito real, é possível senti-lo em todas as células do corpo. O devir abre a forma homem para modos não humanos de individuação. Seu objetivo é abrir para a criação de novos territórios, abre para a criação de novas subjetividades (TRINDADE, 2016, n.p.). 
Desse modo, expomos um jeito de fazer dança na contemporaneidade que está estritamente ligado a ideia de experiência. A dança acontece a partir de fluxos entre o bailarino e o mundo, e não a partir de códigos preestabelecidos ou de uma técnica específica como acontece, por exemplo, no ballet clássico. Assim, a experiência de devir-rio é a base da ação educativa proposta pelo processo criativo do espetáculo. Dewey (1958) comenta que:

[...] a experiência, para ser educativa, deve conduzir a um mundo expansivo de matérias de estudo, constituídas por fatos ou informações, e de idéias. Esta condição somente é satisfeita quando o educador considera o ensino e a aprendizagem como um processo contínuo de reconstrução da experiência (DEWEY, 1958, p. 118).

Pensamos, pois, que no processo do "Rio de Contas", a experiência de entrar em contato com o rio, assim como, com as lembranças e memórias que emergem desse contato são importantes para a construção de um processo educativo transformador que entende o sujeito a partir de sua complexidade.

\section{Afluências- sobre métodos e instrumentos de pesquisa}

É necessário problematizarmos a relação sujeito-objeto na pesquisa qualitativa de abordagem fenomenológica, na medida em que, essa relação não se dá de maneira hierárquica, assim como, o objeto não é inteiramente circunscrito pelo sujeito. A pesquisa revela uma das faces desse objeto, mas nunca sua totalidade. Dessa maneira, a ideia do corpo como objeto da racionalidade é superada. Merleau- Ponty (1994) comenta que:

[...] o corpo não é um objeto. Pela mesma razão, a consciência que tenho dele não é um pensamento, quer dizer, não posso decompô-lo e recompô-lo para formar dele uma ideia clara. [...] Quer se trate do corpo do outro ou meu próprio corpo, não tenho outro meio de conhecer o corpo humano senão vive-lo, quer dizer, retomar por minha conta o drama que ultrapassa e confundi-me com ele (MERLEAU-PONTY, 1994, p. 269).

Assim, a fenomenologia através de seu método possibilita um aprofundamento da relação sujeito-objeto, fazendo com que a experiência da pesquisa seja ainda mais rigorosa e complexa. E para tal, destacamos aqui, a redução fenomenológica, a descrição e a busca das essências como etapas básicas para a pesquisa de abordagem fenomenológica.

No que se refere a redução fenomenológica essa está atrelada a ideia de superação da "atitude natural", ou seja, ultrapassar as ideias preestabelecidas que temos sobre os fenômenos "Dito de outro modo, ela [a fenomenologia] não aceita automaticamente dizer que alguma 
coisa "e", mas procura compreender o que motiva um ser consciente a dizer que alguma coisa “e"” (GIORGI, 2017, p. 391). Faz parte também da redução fenomenológica, o "descarte" de conhecimentos anteriores dos fenômenos, a fim de que, a experiência seja mais satisfatória, pois, "Ocorre muito frequentemente que interpretações anteriores orientem a experiência atual e, neste caso, a situação não se encontre mais determinada por critérios limitantes" (GIORGI, 2017, p. 392).

A descrição, por seu turno, é o meio pelo qual o sujeito corporifica linguisticamente a experiência do fenômeno, tal qual como ele se apresenta (GIORGIO, 2017). Assim, o mesmo fornece a pesquisa, um material possível de ser interpretado pelo pesquisador, a posteriori. No que concerne a "busca das essências", a mesma, se dirige a ideia de esquadrinhar no fenômeno aquilo que lhe é fundamental, sem o qual não se faria em presença. Giorgi (2017) versa que:

Definitivamente, a utilidade do método depende da habilidade do pesquisador em suscitar os possíveis. Tudo que é dado, atendo-se aí aos fatos, torna-se o exemplo de uma possibilidade de ser do fenômeno; e é multiplicando as possibilidades que se chega a destacar as particularidades que permanecem imutáveis, o que é essencial, portanto, para que o objeto seja dado a consciência (GIORGI, 2017, p. 395).

Mas como estas etapas se darão no contexto do espetáculo "Rio de Contas"? Essa questão resvala, inevitavelmente, no objetivo geral da pesquisa "Corpos Flutuantesestratégias de emancipação e aprendizagem através da dança produzida no Vale do São Francisco" tendo, em vista que, esse se direciona ao entendimento do processo criativo do espetáculo ter se feito como um lugar de aprendizagem para a criação de condutas e imagens emancipadas de Sertão. A descrição do processo do espetáculo aliado a redução fenomenológica e a busca das essências são etapas cruciais para a pesquisa, pois, a partir delas poderemos ter acesso a forma como o fenômeno de construção do espetáculo se apresentou a consciência daqueles que fizeram parte do processo, e que, em hipótese, edificaram corpos e imagens emancipadas do contexto local.

A descrição do processo de criação do espetáculo será coletada a partir do uso da entrevista compreensiva, pois, esta busca compreender de maneira contextualizada as falas dos participantes da pesquisa. Ao mesmo tempo em que fornece dados para análise, a entrevista compreensiva, subsidia a compreensão dos fenômenos que deram origem a estes dados.

Segundo Kaufmann (2013, p. 16) “[...] são nas situações de maior intensidade, mas notadamente de maior naturalidade, na interação em campo, que se revelam as camadas mais 
profundas de verdade". Assim, a entrevista será conduzida de modo não hierárquico, buscando um lugar de alteridade com os entrevistados, pois, quando a entrevista é conduzida a distância ou através de questionários que resguardam a presença física do pesquisador, os entrevistados tendem a elaborar suas devolutivas de modo a suprimirem certos posicionamentos, fazendo o uso de "máscaras" que produzem polimentos retóricos nas respostas.

Entendendo que o espetáculo em questão pode ser apreendido enquanto produtor de outras imagens acerca do Vale do São Francisco, e de que a imagem enquanto discurso visual carrega consigo uma série de contradições e paradoxos a respeito daquilo que representa, será adotado, para a coleta e interpretação de documentos iconográficos (fotografias e vídeos), alguns parâmetros da Fenomenologia e da semiótica peirciana, que por sua vez, confere especial atenção ao poder sígnico das imagens. Em relação a semiótica Santaella (1983, p. 13) diz que "[...] é a ciência que tem por objeto de investigação todas as linguagens possíveis, ou seja, examina os modos de constituição de todo e qualquer fenômeno como o de produção de significação e de sentido".

A partir de um tratamento semiótico, propomos perceber as imagens produzidas pelo espetáculo a partir de sua potência fenomenológica de proporcionar ao mesmo tempo uma experiência e um ensinamento (DIDI-HUBERMAN, 2012), que revelem outras perspectivas das representações produzidas sobre o Sertão. Desse modo, as imagens produzidas pelo espetáculo serão analisadas a partir de três etapas: a primeira, diz respeito a análise da imagem em si mesma como produtora sígnica; a segunda análise, se dará a partir da investigação das imagens em relação aos sujeitos produtores dessas; e a terceira, acontecerá a partir da relação com os interpretantes, ou seja, com os efeitos reais ou potenciais que provocam em seu público receptor/intérprete.

\section{Deságue- estados provisórios de uma conclusão}

A pesquisa qualitativa de abordagem fenomenológica no campo das ciências sociais, assim como da educação é deveras recente e carece de problematizações constantes, pois, como expõe Giorgi (2017):

[...] a abordagem fenomenológica não está senão dando seus primeiros passos. Porém, a própria filosofia data de apenas 100 anos. Em todo caso, a relativa juventude dessa abordagem, conjugada a algumas dificuldades intrínsecas, pode ajudar a explicar a razão de suas múltiplas interpretações

(GIORGI, 2017, p. 406- 407). 
Contudo, essa abordagem abriu um campo de possibilidades de análise da vida nunca antes imaginado, pois, a fenomenologia reclama ao pesquisador condutas não dicotomizadas, assim como, relações simétricas de poder, na medida em que questiona a relação sujeitoobjeto e o modo como enxergamos o que nos cerca, além de, pensar o ser de maneira complexa e plural. Essa concepção é deveras importante para a educação na contemporaneidade, pois, “[...] o homem não aprende somente com sua inteligência, mas com seu corpo e suas vísceras, sua sensibilidade e imaginação" (REZENDE, 1990, p. 49).

A abordagem fenomenológica traz em seu cerne um jeito de olhar a vida bastante particular e não menos rigorosa que outras abordagens metodológicas, mas o que nos faz aplicá-la a pesquisa em torno do espetáculo "Rio de Contas" é sua potência de enxergar o ser em suas contradições e paradoxos, de atribuir a ele responsabilidades para com o todo da vida, já que, estar no mundo é um ato de convivência. Consequentemente, a dança e a educação como fenômenos da vida humana são mais bem investigados pela perspectiva fenomenológica, que através de seu método, traz a superfície, os pormenores das relações estabelecidas entre os sujeitos e o mundo nos mais diversos campos da vida humana para que, assim, possamos conhecer o outro, o mundo e a nós mesmos de maneira mais profunda.

Trazemos a esta pesquisa, a imagem da pororoca, do encontro do rio com o mar, geradores de uma força de colisão transformadora que funde rio e mar num território agridoce de comunhão. Pensar a educação, a partir do corpo e das infindáveis relações que ele estabelece com o mundo-da-vida é colocá-lo nesse espaço de pororoca, de perturbações e movimentos de tensões necessários a vida na contemporaneidade, que se faz em constante transformação. Assim, o ensino deve ser compreendido "[...] como atitude de favorecer experiências de aprendizagem mais envolventes, que permitam ao indivíduo problematizar a sua própria existência sendo capaz de agir criativamente no espaço de convivência" (PORPINO, 2006, p. 120).

Podemos perceber a dança como esse território agridoce de construção política, poética e ética de possibilidades e experiências infindáveis. A educação pela dança para a construção de uma corporeidade emancipadora, geradora de conhecimento sobre o mundo, é deveras necessária para compreendermos nossa existência neste cosmo, para que possamos superar antigas perspectivas e jeitos de ver o mundo, alicerçadas de maneira fragmentária, dicotômica e de supremacia do homem sobre a Terra. Desse modo, reclamamos por uma educação que se faça em poesia, pois, como intenta Morin (1998, p. 9) é possível reconhecer a poesia “[...] não apenas como um modo de expressão literária, mas como um estado segundo do ser que advém 
da participação, do fervor, da admiração, da comunhão, da embriaguez, da exaltação e, obviamente, do amor, que contém em si todas as expressões desse estado segundo".

\section{Referências}

DELEUZE, G.; GUATTARI, F. Mil Platôs: capitalismo e esquizofrenia. São Paulo: Ed. 34, 1997. v. 4.

DEWEY, J. Experiência y Educación. Buenos Aires: Editorial Losada, 1958. 125p.

DIDI-HUBERMAN, G. Quando as imagens tocam o real. In: Pós revista do programa de pós-graduação em artes da escola de belas artes da UFMG, Belo Horizonte, v.2, n.4, nov. 2012.

FOUCAULT, M. Vigiar e punir. Petrópolis: Vozes, 1987.

GIORGI. A. Sobre o método fenomenológico utilizado como modo de pesquisa qualitativa nas ciências humanas: teoria prática e avaliação. In: POUPART, J; DESLAURIERS, J.P; GROULX, L; LAPERRIÉRE, A; MAYER, R; PIRES, A, P. A pesquisa qualitativa: enfoques epistemológicos e metodológicos. Trad. Ana Cristina Nasser. Petrópolis/RJ: Vozes, 2017.

HEIDEGGER, M. Ser e Tempo (parte I). Petrópolis: Vozes, 1995.

KAUFMANN, J. C. A entrevista compreensiva: um guia para pesquisa de campo. Petrópolis/Maceió, Vozes/Edufal, 2013.

LARA. L. Arqueologia de um processo criativo: um livro coreográfico. Brasília: Anti Status Quo Companhia de Dança, 2010.

MARTINS, J. Um enfoque fenomenológico de currículo: educação como poiésis. São Paulo: Cortez, 1992.

MERLEAU-PONTY, M. A fenomenologia da percepção. Trad. Carlos Alberto Ribeiro de Moura. Rio de Janeiro: Martins Fontes, 1994.

MERLEAU-PONTY, M. O visível e o invisível. São Paulo: Perspectiva, 1999.

MORIN, E. Amor, poesia, sabedoria. 2. Ed. Trad. Edgard de Assis Carvalho. Rio de Janeiro: Bertrand Brasil, 1998.

NÓBREGA, T.P. Para uma teoria da corporeidade: um diálogo com Merleau Ponty e o pensamento complexo. Piracicaba-SP. Tese (Doutorado em educação) Universidade Metodista de Piracicaba, 1999.

PORPINO. K. O. Dança é educação: interfaces entre corporeidade e estética. Natal: EDUFRN, 2006. 
REZENDE, A. M. Concepção Fenomenológica da Educação. São Paulo: Cortez, 1990.

SANTAELLA, L. O que é semiótica? São Paulo: Brasiliense, 1983.

TRINDADE, Rafael. Devir- revolucionário. Razão Inadequada, 2016. Disponível em:

<https://razaoinadequada.com/2016/03/23/devir-revolucionario/>. Acesso em: 20 out. 2018. 